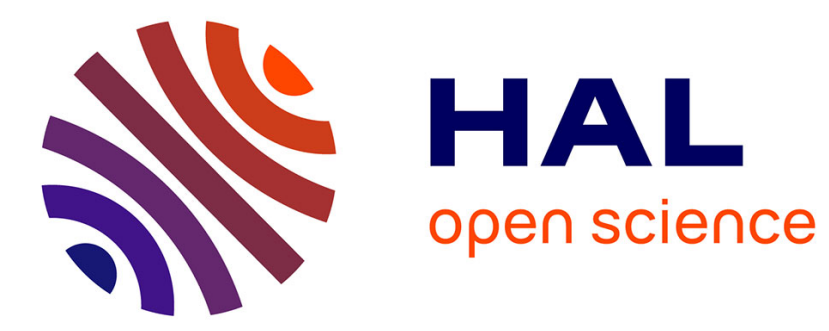

\title{
Towards passive cooling solutions for mobile access network
}

\author{
Stéphane Le Masson, David Nörtershäuser, Denise Mondieig, Hasna \\ Louahlia-Gualous
}

\section{To cite this version:}

Stéphane Le Masson, David Nörtershäuser, Denise Mondieig, Hasna Louahlia-Gualous. Towards passive cooling solutions for mobile access network. Annals of Telecommunications - annales des télécommunications, 2012, 67 (3), pp.125-132. 10.1007/s12243-011-0283-6 . hal-00685249

\section{HAL Id: hal-00685249 \\ https://hal.science/hal-00685249}

Submitted on 30 Aug 2018

HAL is a multi-disciplinary open access archive for the deposit and dissemination of scientific research documents, whether they are published or not. The documents may come from teaching and research institutions in France or abroad, or from public or private research centers.
L'archive ouverte pluridisciplinaire HAL, est destinée au dépôt et à la diffusion de documents scientifiques de niveau recherche, publiés ou non, émanant des établissements d'enseignement et de recherche français ou étrangers, des laboratoires publics ou privés.

\section{(1)(1) $\$(0)$}

Distributed under a Creative Commons Attribution - NonCommercial - ShareAlikel 4.0 


\title{
Towards passive cooling solutions for mobile access network
}

\author{
Stéphane Le Masson • David Nörtershäuser · \\ Denise Mondieig • Hasna Louahlia-Gualous
}

\begin{abstract}
The amount of electricity used by mobile networks has become an important issue in recent years as demand for new services has become more widespread. In 2006, energy consumption of Orange mobile network was estimated at $290 \mathrm{GWh}$ per year. Recent works show that thermal architecture must be improved in order to increase thermal efficiency of buildings, shelters, and outdoor cabinets. This paper shows some new approaches on thermal management for telecom enclosures in order to reduce energy consumption of this network.
\end{abstract}

Keywords Thermal · Ventilation · Thermosyphon loop · Phase change material

\section{Introduction}

Telecom shelters and outdoor cabinets are widely used either for mobile phone base stations or for placing xDSL

S. Le Masson $(\varangle) \cdot D$. Nörtershäuser

Orange Labs R\&D, RESA/DEAN,

2, Av Pierre Marzin,

22300 Lannion, France

e mail: stephane.lemasson@orange.com

D. Mondieig

CPMOH Centre de Physique Moléculaire et Optique Hertzienne,

UMR 5798 au CNRS Université Bordeaux I,

351 Cours de la Libération,

33405 Talence, France

H. Louahlia Gualous

Université de Caen Basse Normandie, LUSAC,

IUT de Cherbourg Manche,

120 rue de l'Exode,

50000 Saint Lô, France equipments close to the customer. As the power dissipated by the equipments grows tremendously throughout the generations, heat management is necessary and becomes an important issue.

According to the politics of sustainable development of France Telecom and European Telecommunication Standards Institute (ETSI) [1] environment standards for telecommunication equipments, a study has been led in order to optimize the conception of telecom shelters and outdoor cabinets.

This paper shows thermal issue of telecommunication equipments located in access network. New cooling solutions are proposed in order to reduce energy consumption of cooling and increase energy efficiency. These solutions are based on using of fresh air and new passive solutions using phase change materials or thermosyphon loop.

\section{Thermal issue}

Thermal issue is described below in Fig. 1. Thermal load is done by electronic telecommunication racks. External loads are usually external temperature and solar heat flux. Building walls could play an important role in thermal heat transfer. Some works show the importance of this heat transfer from chipset to buildings [2, 3]; numerical simulations are performed in order to define building rules that need to be followed to achieve a high-performance structure. Following questions are asked:

- Is it necessary to use thermal insulation? Internal or external?

- What are the ideal thermal properties for the building?

- Which air cooling management is better or "more green"? 
Fig. 1 Thermal issue with internal and external loads

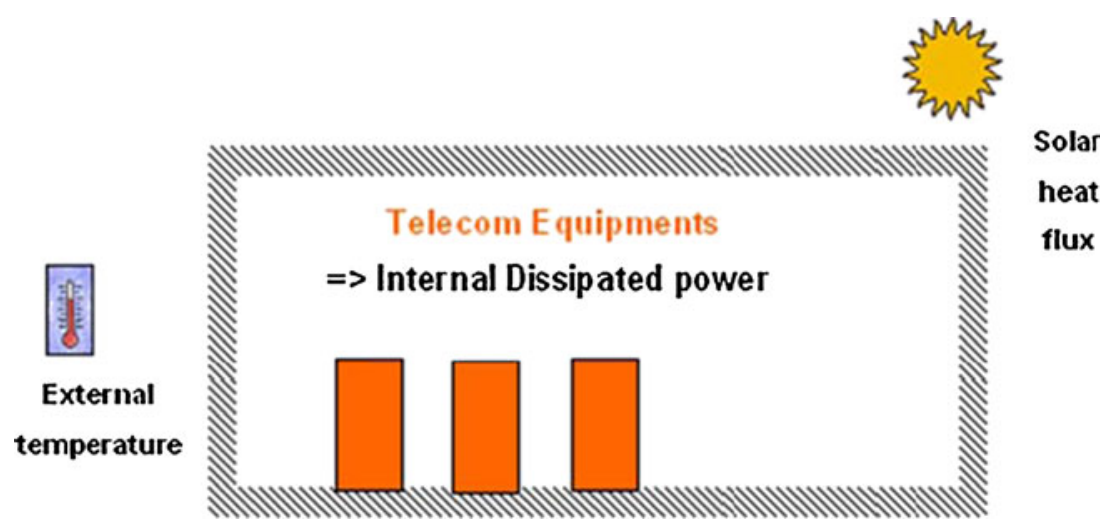

General governing equation is the following where subscript $i$ is related to the face of the domain.

$\dot{Q}+\sum_{i} \dot{m}_{i}\left(h_{i}+\frac{1}{2} V_{i}^{2}\right)=\frac{d}{d t}\left[m\left(h+\frac{V^{2}}{2}\right)\right]$

Where

" $\dot{Q}$ " is the heat load, " $\dot{m}_{i}$ " the flow rate through face $i$, " $h_{\mathrm{i}}$ " the mass enthalpy through, $m$ the internal mass with a velocity "V" and an enthalpy "h."

\section{Ventilation}

In order to cool electronic cabinet or shelter, it is very useful to use simple ventilation instead of air conditioning with cold production. For very low heat dissipation, it is possible to use natural convection. The fluid flow is moved naturally

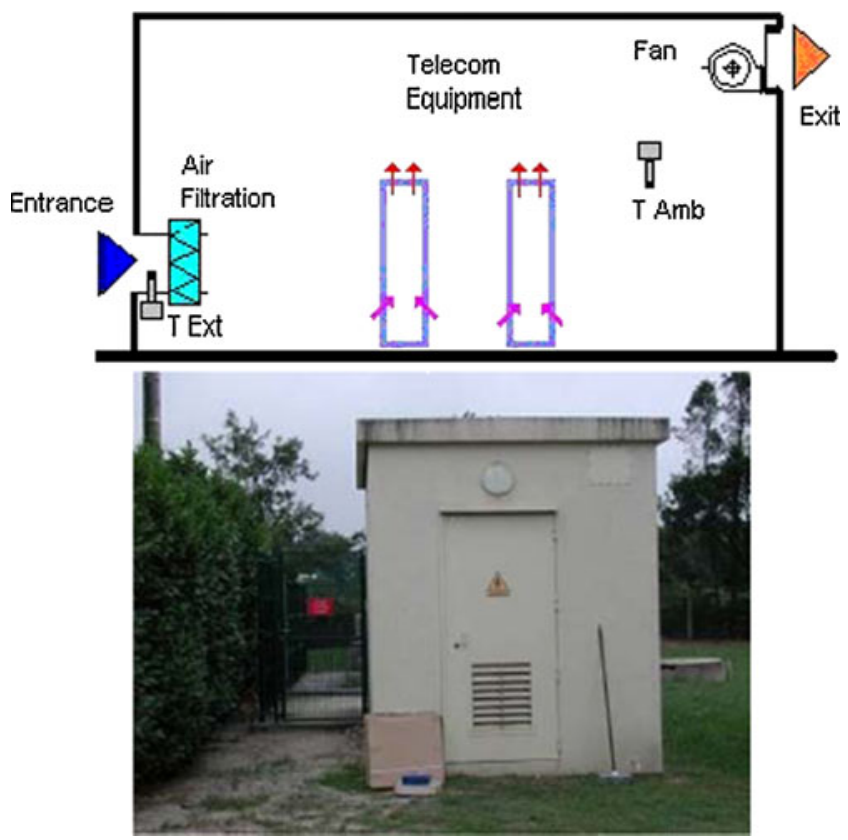

Fig. 2 Telecom shelter with variable speed ventilation. a Schematiza tion, b photography by buoyancy forces. In this situation, heat exhausting capacity is very low and the limit temperature is reached for very low heat dissipations.

Above these limits, forced convection must be used. In this case, the hot air is blown through the building by one fan or more, care must be taken at the entrance for air filtration in order to remove dust particles from refreshing air. Two kinds of ventilation are developed here, variable speed ventilation for shelter or outdoor cabinets and optimized ventilation for concrete buildings. Opening locations and sizes are very important in order to optimize the air flow path.

\subsection{Variable speed ventilation}

When building's thermal inertia is low, variable speed ventilation is useful. Fresh air passes through telecommunication racks. The hot air issuing from the racks is evacuated outside with a variable speed fan as shown in Fig. 2.

Figure 3 below shows the regulation law used for variable speed ventilation, the flow rate is proportional to ambient temperature measured inside the building. As ambient temperature is below $T_{\min }$, the flow rate is null. When ambient temperature is above $T_{\min }$ and below $T_{\max }$, flow

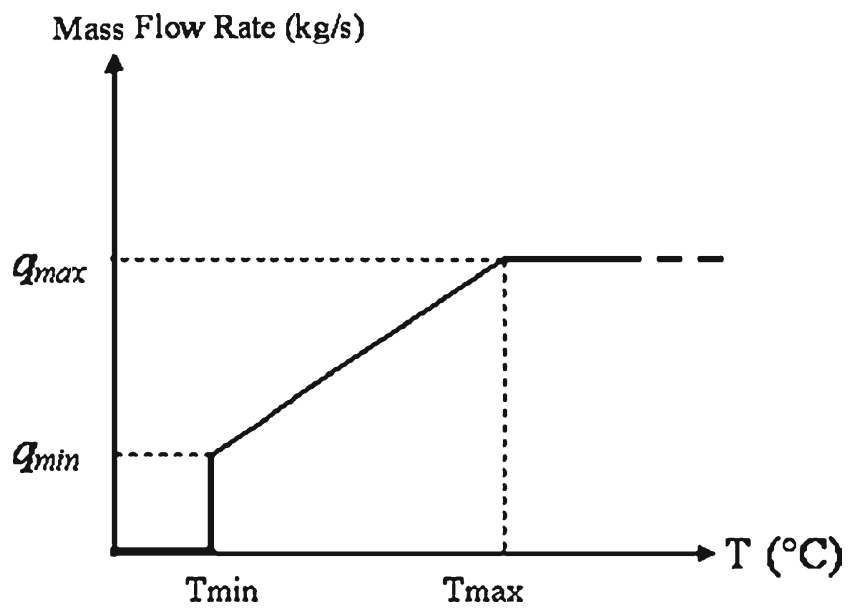

Fig. 3 Regulation law for variable speed ventilation 
Fig. 4 Evolution of temperatures measured inside (pink line) and outside a shelter (blue line) with variable speed ventilation
Temperatures measured with variable speed ventilation

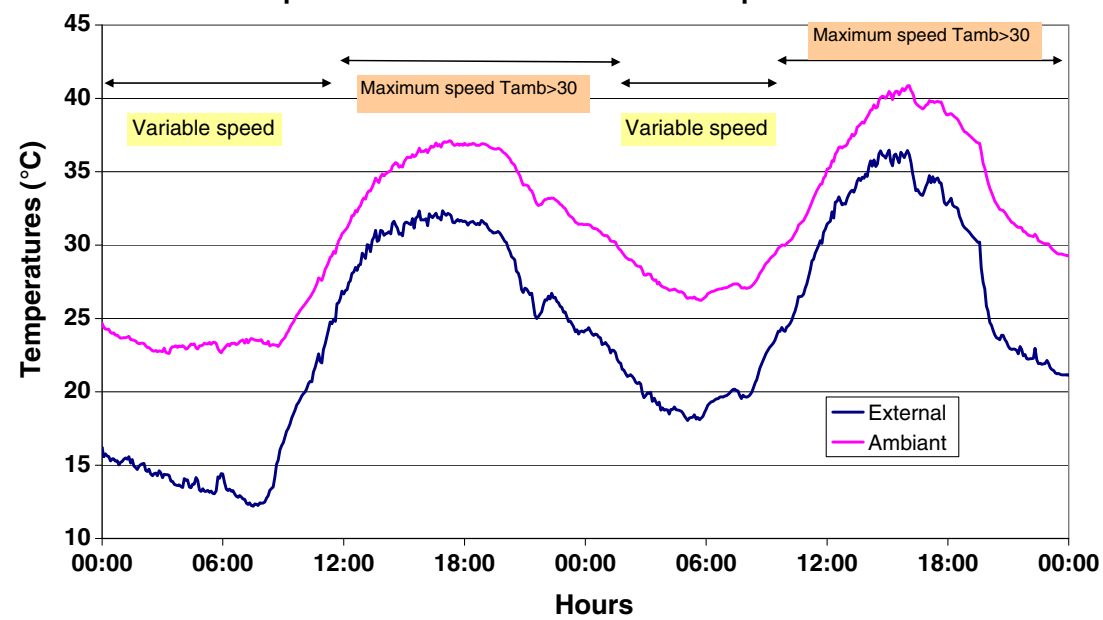

rate is proportional to ambient temperature; above $T_{\max }$ the flow rate is equal to $q_{\max }$.

Figure 4 below, shows an example of temperature measured inside and outside a typical telecom shelter located in southwest of France. The dimensions of the shelter are $3 \times$ $2.2 \times 2.7 \mathrm{~m}$, thermal load is $8.4 \mathrm{~kW}$, setting point are $25^{\circ} \mathrm{C}$ for $T_{\min }$ (flow rate $=0$ ) and $40^{\circ} \mathrm{C}$ for $T_{\max }$ (flow rate is $2,700 \mathrm{~m}^{3} \mathrm{~h}^{1}$ ).

In this situation, the inside temperature is always above the external temperature.

\subsection{Optimized ventilation}

Optimized ventilation, could be used if the building thermal inertia is high, for example, when walls are made with concrete. In this situation, night coolness can be used.
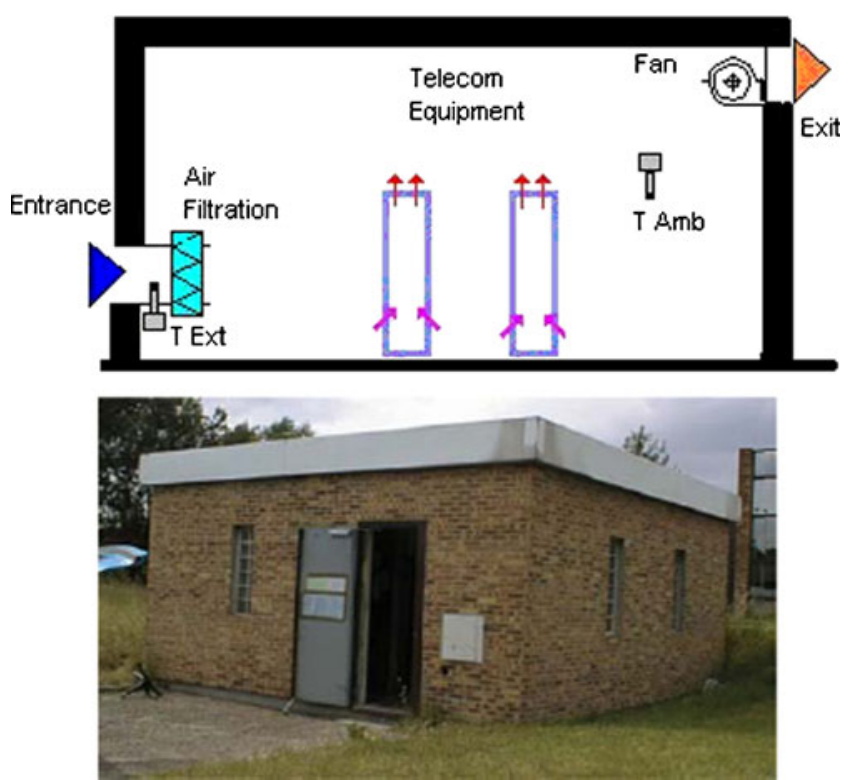

Fig. 5 Telecom building with high thermal inertia cooled with opti mized ventilation. a Schematization, b photography
The airflow is controlled by a proportional law depending on the difference between a temperature of reference and the blowing temperature. The temperature of reference must be representative of the heating of the air passing through the equipment room. Usually, the difference of temperature is kept at $8^{\circ} \mathrm{C}$ or $10^{\circ} \mathrm{C}$ depending on the type of telecommunication equipment. Another method of control could be appropriate in this case, assuming that the generated temporal gradients remain within the limits of the standard $\left( \pm 0.5^{\circ} \mathrm{C} /\right.$ min integrated over $5 \mathrm{~min}$ ). The principal goal of this law is to adapt automatically the flow according to the power of the equipment. Indeed, for the same temperature of blowing, the increase in the power leads to a rise in the temperature of reference and thus in the flow. Figures 5 and 6 show a representation of this concept and the governing flow rate law.

Figure 7 shows temperatures measured in telecom small building cooled with optimized ventilation. In this case, when the difference of temperature between external and internal is below a fixed limit, the ventilation is stopped (at 10 a.m. in this example). In this example, thermal heat dissipation is $1.8 \mathrm{~kW}$ and the localization is near Bordeaux in France. Temporal evolution of the internal temperature is limited by heat exchange between cold walls and ambient

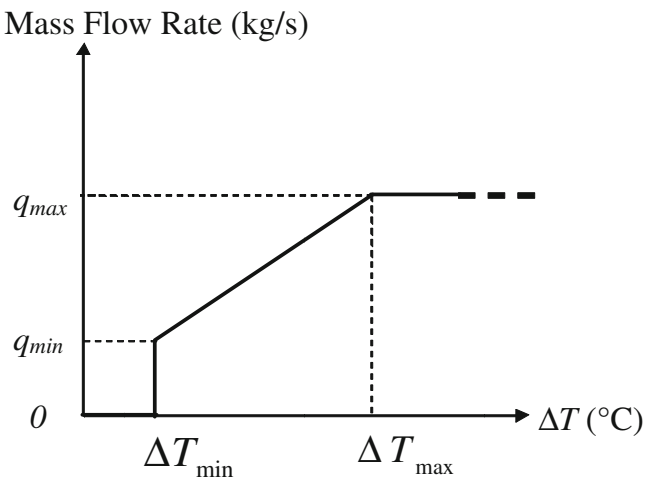

Fig. 6 Regulation law for optimized ventilation 
Fig. 7 Evolution of temperatures measured inside and outside a building with optimized ventilation

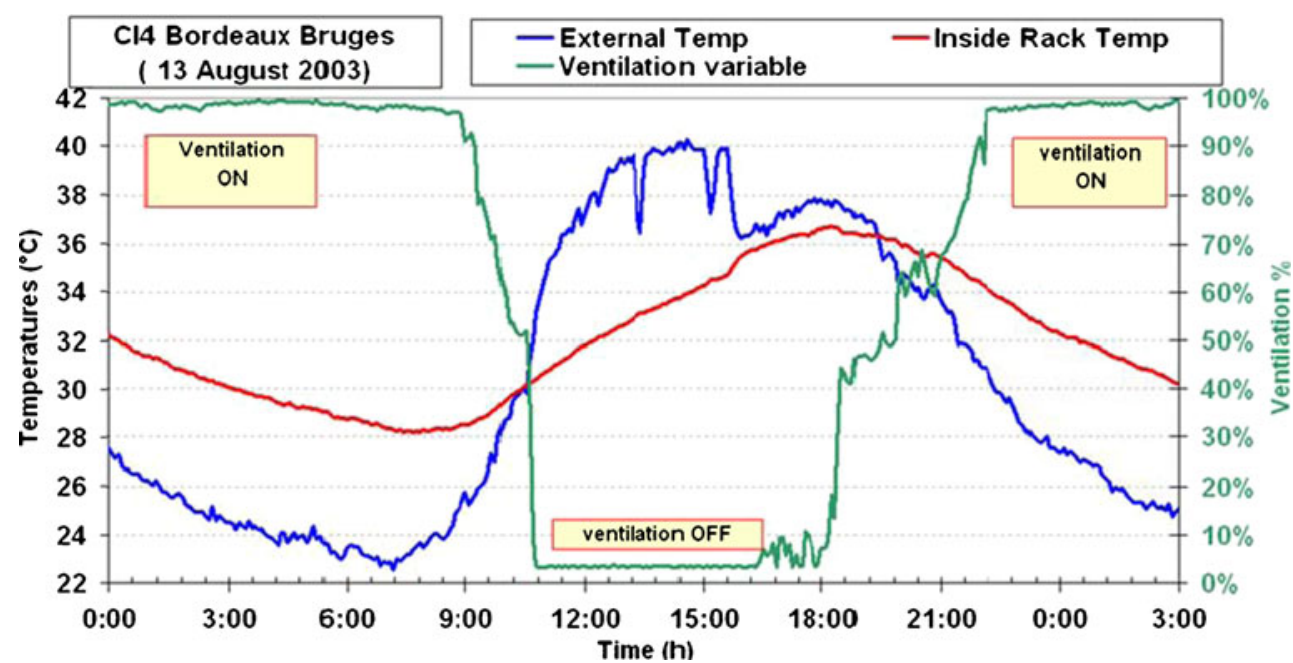

air, no more external hot air is blown inside the building because the internal temperature is lower than external temperature.

When the inside and outside temperatures are quite similar, the ventilation starts with a very low flow rate in order to reduce thermal gradients. In this case, the internal temperature can be below external temperature even in summer.

Energy efficiency has been measured and this ventilation can reduce air cooling consumption by eight to ten times versus active air cooling (like typical split system).

\section{Phase change material}

A phase change material (PCM) is a material whose molecular structure changes at a certain temperature (or range of temperature) [4-11]. A great amount of energy is needed for the phase change to occur. This particularity can be used to limit the temperature variation of a thermal system. There are several types of phase change materials. Liquid/ solid materials seem to be the suitable product for the buildings.

Micro-encapsulated products can be incorporated in gypsum plaster, concrete or different kinds, or mortars [3], but molecular alloys, with a high latent transition heat, can be used for thermal storage process, if the energy exchanged during the phase transition is sufficient and the temperature adapted to the application temperature.

During the melting process, the alloy stores latent heat, energy that is restored during the solidification process. For example, Fig. 8 shows the evolution of the temperature inside PCM (red curve) when an external cooling process is imposed (green curve) near phase change temperature $\left(36^{\circ} \mathrm{C}\right), \mathrm{PCM}$ temperature and imposed temperature are very different due to the effect of latent heat.

The thermal window is defined as the difference between the solidus and liquidus temperatures. In industrial applications, we need to keep the air refreshing the equipment at a fixed constant temperature. We need also a narrow thermal window in order to regenerate PCM easily.
Fig. 8 Example of PCM temperature evolution
MCP temperature evolution : cooling

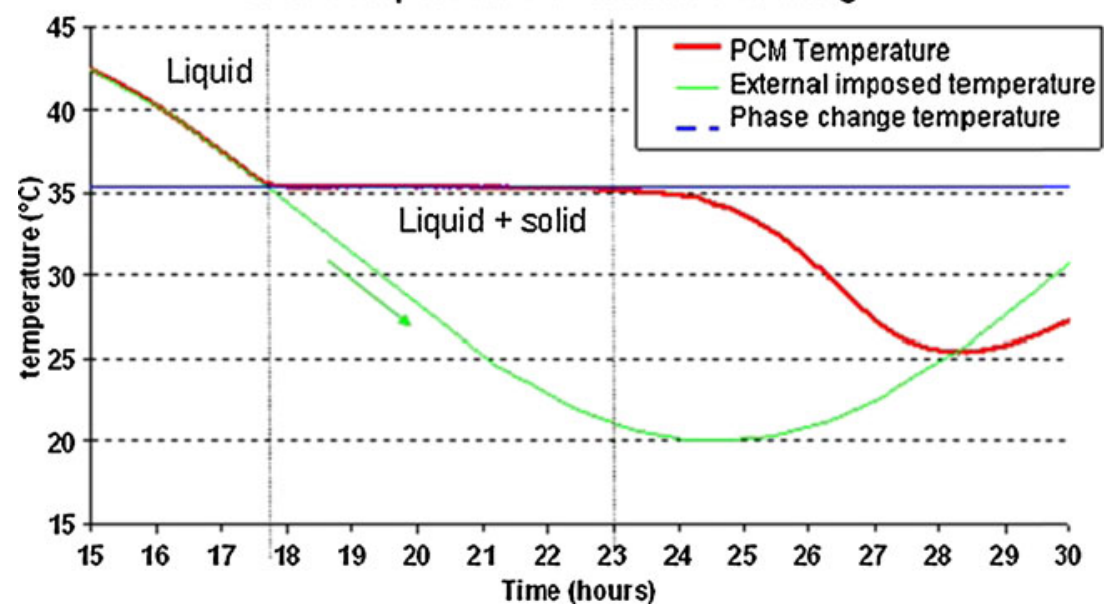


Fig. 9 Visualization of PCM melting process

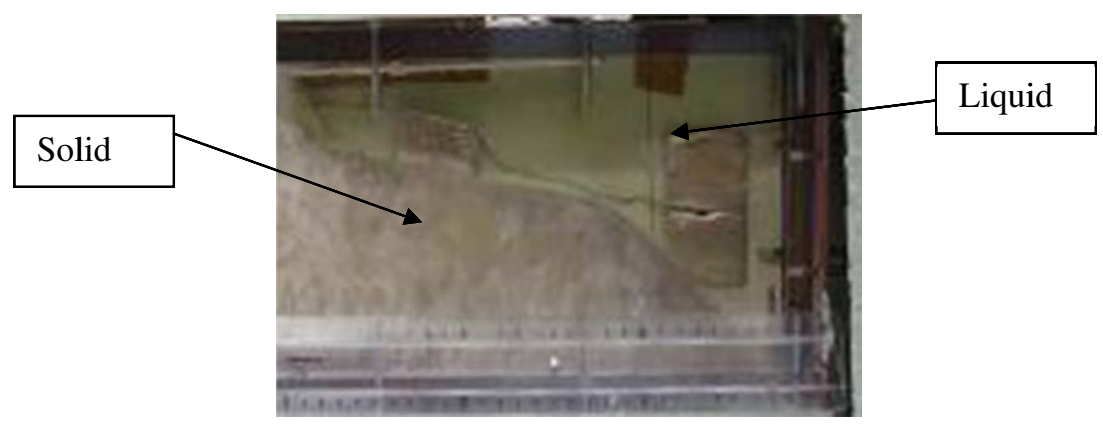

Figure 9 shows a visualization of the PCM melting process. A hot plate, at constant temperature above phase change temperature, is located on the right side of this picture.

Visualizations are done in a rectangular box with chosen aspects ratio, in order to have bi-dimensional thermal problem. It is shown that displacement of the front between solid and liquid is not straight. Liquefaction process is not done only by conduction; there are convection motions due to buoyancy effects near heated plate. Heat transfer inside PCM is not so easy to be understood.

In our case, according to ETSI limits, it is more interesting to use PCM with phase change temperature just below $55^{\circ} \mathrm{C}$. We have done some researches in order to find the right molecular formulation (phase change temperature $=51^{\circ} \mathrm{C}$, latent heat $=150 \mathrm{Jg}^{1}$ ). Experimental measurements have been performed in an outdoor cabinet with heating card (Fig. 10, on the right hand side), $2 \mathrm{~kg}$ of PCM are located inside ten heat exchangers located at the bottom of the cabinet. Heat exchanger $\left(15 \times 15 \times 3 \mathrm{~cm}^{3}\right)$ are made in aluminum, fins are located outside and inside in order to increase heat transfer inside and outside. Temperatures are measured by thin thermocouple linked to an acquisition system, temperatures are recorded every $10 \mathrm{mn}$ at several locations. The outdoor cabinet is located inside a climatic chamber [12] in which temperature and solar radiation are simulated in order to recreate idealized unsteady temperatures and solar heat flux.

Figure 11 shows an example of temperatures measured at equipment entrance (just below heating cards), for heating power of $100 \mathrm{~W}$, and a simulated climate relative to south of France. For a solar heat flux of $600 \mathrm{~W} / \mathrm{m}^{2}$ and an external temperature varying from $22^{\circ} \mathrm{C}$ to $40^{\circ} \mathrm{C}$, the temperature at telecom equipment entrance is just above ETSI limit.

In Fig. 11, red line is the temperature measured without PCM, the black one is the temperature measured with PCM.

Using PCM can reduce maximum temperature; in this example, the reduction is near $5^{\circ} \mathrm{C}$ or more. Heat exchangers must be studied; in this example, it is clear that heat exchange is not optimized.
Fig. 10 Experimental setup. Outdoor cabinet (A); heat exchanger inside view (B); heat exchanger outside view $(\mathbf{C})$

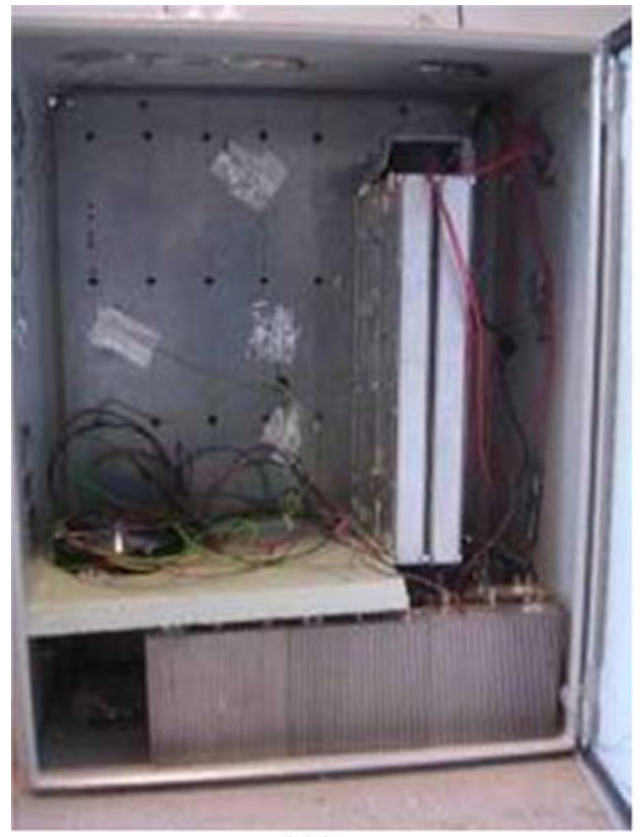

(A)

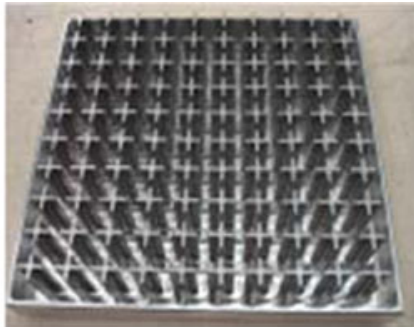

(B)

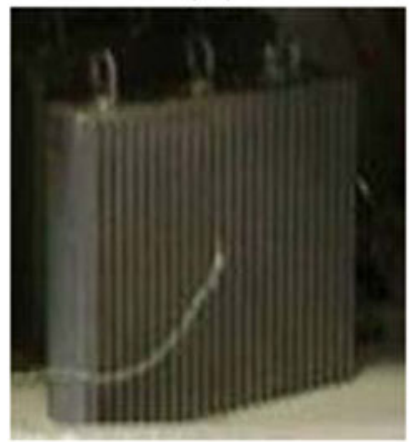

(C) 
Fig. 11 Temperature measured with and without PCM exchangers
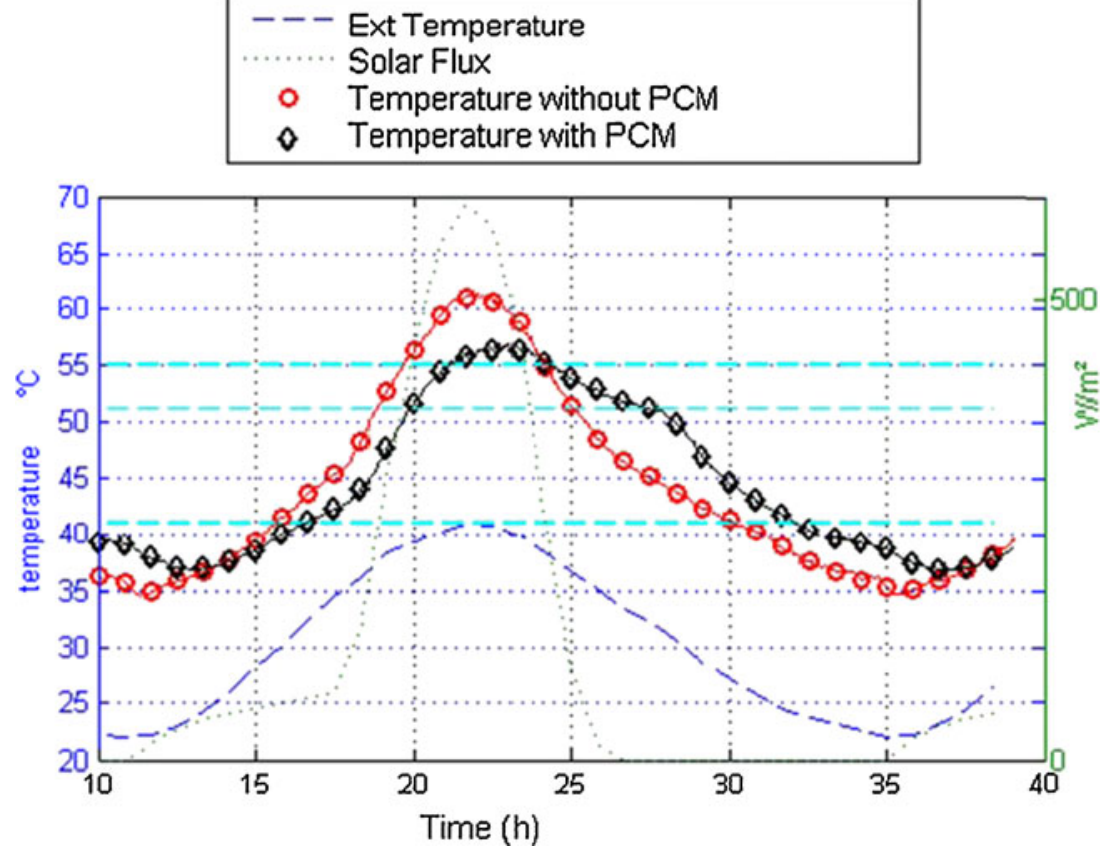

\section{Thermosyphon loop}

Thermosyphon loop is one of the passive cooling systems which have been widely studied [13-17]. It is used in various practical situations: in the chemical industry, in the solar applications for energy storage, in the electronic and telecommunication systems. Thermosyphon loop consists of two principal components: condenser and evaporator, where the working fluid passes from the liquid to vapor phase by dissipating the heat flux (Fig. 12). Vapor moves along the vapor line from evaporator to condenser under the buoyancy force. In condenser, the produced vapor is condensed and the heat flux is transferred from the working fluid to ambient. The condensed fluid is returned to the evaporator entrance under the effect of the gravity force.

In the present study, a thermosyphon cooling module has been developed and tested for cooling electronic circuits in the telecommunication outdoor cabinets because forced air cooling is not efficient enough at high heat flux density and in dusty environment. Operating temperature of the electronic equipment should be less than $55^{\circ} \mathrm{C}$ [1]. $n$-Pentane is chosen as the working fluid because it has a lower saturation temperature at atmospheric pressure $\left(T_{\text {sat }}=35^{\circ} \mathrm{C}\right)$. In this paper, experimental investigation of the thermosyphon loop using mini-channels is conducted. Tests are made with different heating power input ranging from 100 to $450 \mathrm{~W}$. Thermal management of the cooling loop is analyzed for different experimental conditions. Figure 13 below shows the experimental setup: outdoor cabinet with heating cards, thermocouples, and thermosyphon loop. A fan is located near the condenser in order to increase heat exchange, because in this case, condenser is too small.
Figure 14 shows the temporal operating temperatures measured inside the outdoor cabinet for different power supplies $(100,130$, and $160 \mathrm{~W})$. Tests are conducted with two cooling systems placed inside the outdoor telecommunication cabinet.

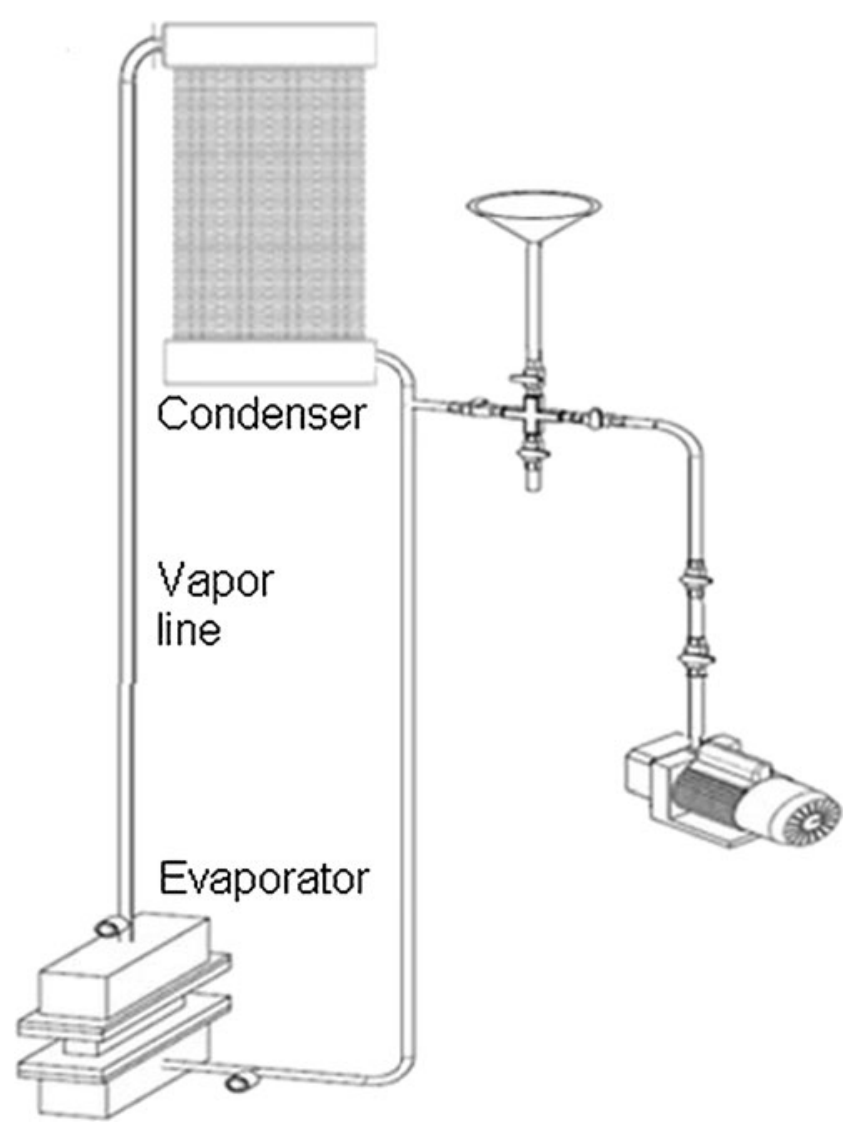

Fig. 12 Schematization of thermosyphon loop 


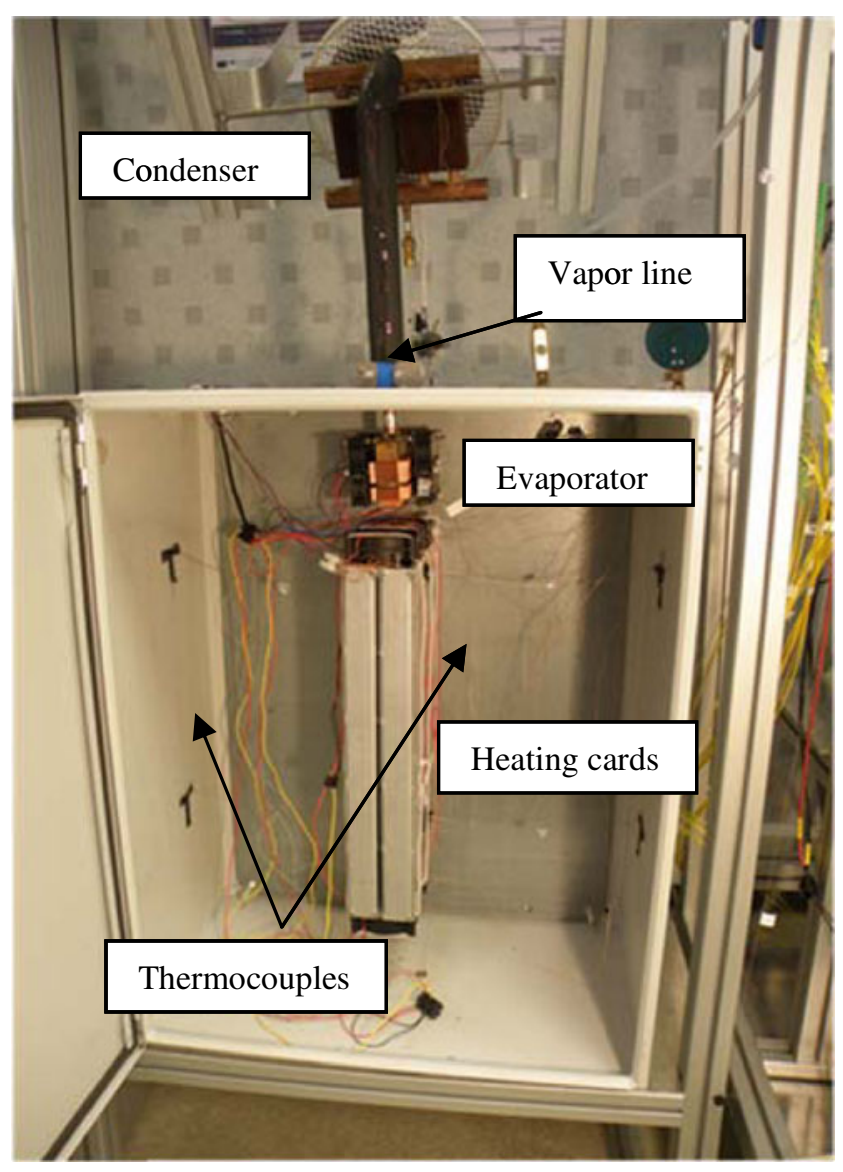

Fig. 13 Telecommunication cabinet with cooling loop

The first one uses the air forced convection flow inside the heating bloc in order to mix heat inside the cabinet. The second cooling system uses the thermosyphon loop as shown in Fig. 12.

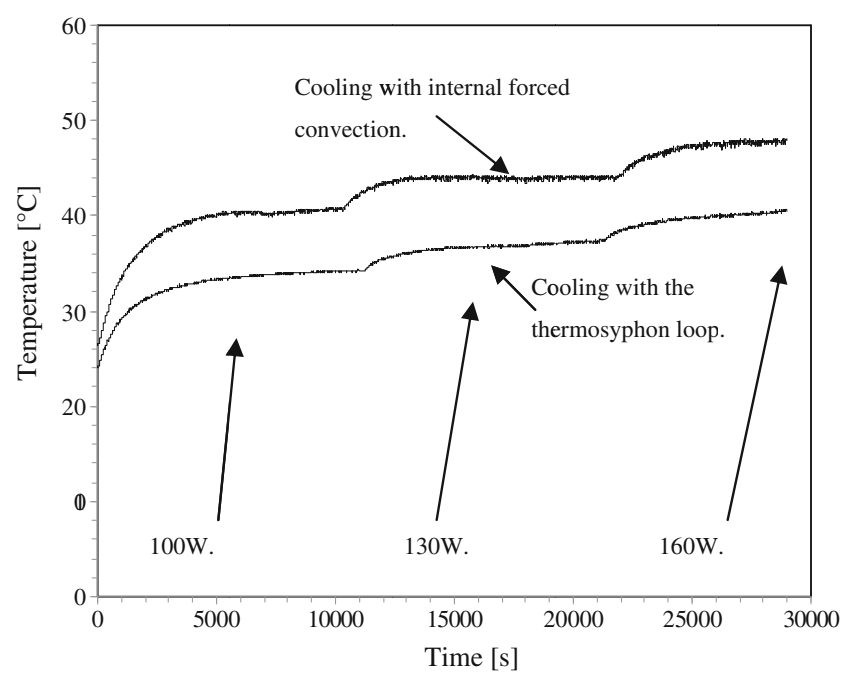

Fig. 14 Temporal operating temperature of the outdoor cabinet
Figure 15 shows operating temperatures measured at steady state with forced convection and with thermosyphon loop for different heating power inputs.

It can be seen that for both cooling systems, the operating temperature increases by increasing the power input. However, the operating temperature is reduced by using thermosyphon loop. For power supplies of telecommunication equipments ranging from 100 to $450 \mathrm{~W}$, it can be noted that the operating temperature is always below $55^{\circ} \mathrm{C}$. This figure shows that the operating temperature varies very slightly at high heat power and it tends to stabilize at approximately $52^{\circ} \mathrm{C}$. This figure shows also that the power dissipated (and then access customers numbers) inside the outdoor cabinet is higher when thermosyphon loop is used with respect to ETSI limits. That means that using thermosyphon loop could increase the number of customers linked to this cabinet.

\section{Conclusion}

Telecom shelters and outdoor cabinets are widely used either for mobile phone base stations or for DSL access networks. Thermal management of such cabinet or building has to be optimized in order to reduce energy impact.

Ventilation is a very simple principle and gives us interesting results; some restrictions appear in particular in dusty atmosphere.

Phase change material is a good way to reduce temperature inside outdoor cabinet. Experimentation has been done in a small cabinet and significant reduction of temperature is shown when heat exchangers with PCM are used. This work has been performed with pure PCM; some new studies must be done in order to find industrial products with high performances.

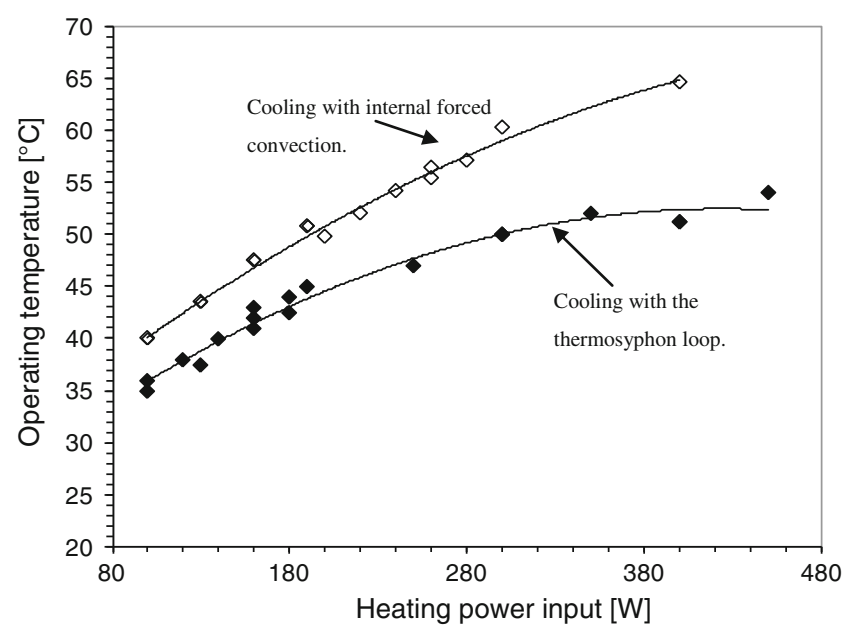

Fig. 15 Cabinet operating temperature for different power supplies 
A new thermosyphon cooling module has been studied and the experimental results are analyzed. It showed that the passive cooling loops using working fluid in phase change are the useful systems. The tested module of the thermosyphon showed the good start-up time for different power input. The system may dissipate the heating power of telecommunication cards up to $450 \mathrm{~W}$. The operating temperature measured inside the outdoor telecommunication cabinet seems to be stable at high heating flux of the telecommunication cards.

\section{References}

1. ETSI EN 300 019, Environmental conditions and environmental tests for telecommunications equipment

2. Anandan S, Ramalingam V (2008) Thermal management of elec tronics: a review of literature. Therm Sci 12(2):5 26

3. Deddy $\mathrm{B}$ et al. Etude de l'intégration de Matériaux à Changement de Phase dans des parois de bâtiments destinés aux télécommuni cations. SFT 2010 May 2010 Le Touquet France

4. Nörtershäuser D, Le Masson S (2007) Using phase change materi als and efficient coldless air conditioning systems to optimize the heat management in telecom shelters IEEE Intelec 2007 Rome, Italy

5. Nörtershäuser D et al. (2006) Application of molecular alloys as phase change materials for limiting the rise of temperature in telecommunication outdoor cabinets. IHTC Sydney 2006

6. Ibanez M, Lazaro A, Cabeza L (2005) An approach to the simu lation of PCMs in building applications using TRNSYS. Appl Therm Eng 25:1796 1807
7. Zhu N, Ma Z, Wang S (2009) Dynamic characteristics and energy performance of buildings using phase change materials. Energ Convers Manag 50:3169 3181

8. Ventolà L et al (2002) From concept to application. A new phase change material for thermal protection at $11^{\circ} \mathrm{C}$. Mat Res Innovat 6:284 290

9. Ventolà L et al (2005) Molecular alloys as phase change materials (MAPCM) for energy storage and thermal protection at tempera ture from 70 to $85^{\circ} \mathrm{C}$. J Phys Chem Solids 66:1668 1674

10. Metivaud V et al (2005) Hexadecane +1 Hexadecanol binary sys tem: crystal structure of the component and experimental phase diagram. Application of thermal protection of liquids. Chem Mas ter 17:3302 3310

11. Mondieig D et al (1994) Molecular alloys as phase change materi als (MCPAM) for the storage of thermal energy. Mat Res Bul 26:1091 1099

12. Nörtershäuser D et al. (2005) Clim@Lan: a powerful artificial climate facility designed to test telecommunication equipments. IEEE Intelec Berlin

13. Joung W, Yu T, Lee J (2008) Experimental study on the loop heat pipe with a planar bifacial wick structure. Int J Heat Mass Trans $51: 15731581$

14. Greif R (1980) Natural circulation loops. ASME J Heat Transfer 110:1243 1258

15. Mc Menamy JW, Homan KO. Transient behaviour of a free con vection loop communicating with a finite reservoir. Int J Heat and Fluid Flow (in review)

16. Nam SS, Choi SB, Kim JH, Kwak HY (1998) Transient character istics of two phase thermosyphon loop for multichip module. ETRI Journal 20:284 300

17. Khordabandech R (2005) Heat transfer in the evaporator of an advanced two phase thermosyphon loop. Int $J$ Ref $28: 190202$ 